\title{
Antenatal oral dexamethasone for neonatal respiratory distress syndrome increased neonatal morbidity
}

\author{
Egerman RS, Mercer BM, Doss JL, et al. A randomized, controlled trial of oral and intramuscular dexamethasone in the prevention \\ of neonatal respiratory distress syndrome. Am J Obstet Gynecol 1998 Nov;179:1120-3.
}

\section{Question}

Is antenatal oral dexamethasone as efficacious and safe as intramuscular dexamethasone for reducing neonatal respiratory distress syndrome?

\section{Design}

Randomised controlled trial.

\section{Setting}

USA.

\section{Patients}

170 women who were 24-33 weeks gestation and had preterm labour, preterm rupture of membranes, or a medical indication for delivery. Women were excluded if they had previously received corticosteroids during the pregnancy, had received anticonvulsant treatment or rifampin, had an infection other than cystitis or cervicitis, had advanced cervical dilation $(\geqslant 5 \mathrm{~cm})$, or had known fetal pulmonary maturity through amniocentesis or vaginal pool sampling. 5 women were unavailable for follow up.

\section{Intervention}

Women were allocated to dexamethasone, $8 \mathrm{mg}$ orally $(\mathrm{n}=92)$ or dexamethasone, $6 \mathrm{mg}$ intramuscularly $(\mathrm{n}=78)$ every 12 hours for 4 doses. The regimen was repeated weekly until 34 weeks gestation if delivery had not yet occurred.

\section{Main outcome measures}

Main outcome was neonatal respiratory distress syndrome, diagnosed in infants with an oxygen requirement of $>40 \%$ and symptoms of respiratory distress syndrome, confirmed by chest radiography. Secondary outcomes were sepsis, intraventricular haemorrhage, necrotising enterocolitis, and neonatal death.

\section{Main results}

165 women were included in the intention to treat analysis. 99 infants were born to women in the oral group and 84 infants were born to women in the intramuscular group. The groups did not differ for the frequency of respiratory distress syndrome (34.3\% in the oral group $v 29.8 \%$ in the intramuscular group, $\mathrm{p}=0.53)$. Infants of mothers who received oral dexamethasone had increased rates of sepsis $(10.1 \% v 1.2 \%, \mathrm{p}=0.01)$ and intraventricular haemorrhage $(10.1 \% v 2.4 \%, \mathrm{p}=0.04)$, but did not differ for rates of necrotising enterocolitis $(6.1 \% v 1.2 \%, \mathrm{p}=0.13)$ or neonatal deaths $(7.1 \% v 4.8 \%, \mathrm{p}=0.55)$. Subgroup analyses of women who delivered before 34 weeks gestation $(n=112)$ showed similar results.

\section{Conclusion}

Infants of women who received oral antenatal dexamethasone had similar rates of neonatal respiratory distress syndrome as infants of women who received antenatal intramuscular dexamethasone, but had higher rates of sepsis and intraventricular haemorrhage.

\section{Source of funding: none stated.}

For correspondence: $\operatorname{Dr} R S$ Egerman, Department of Obstetrics and Gynecology, University of Tennessee, Memphis, 853 Jefferson, Suite E 102, Memphis, TN 38103, USA. Fax +1 9014484701.

\section{Commentary}

Preterm delivery occurs in $11 \%$ of all pregnancies and is a major cause of perinatal mortality and morbidity. ${ }^{1}$ The benefits of prophylactic corticosteroids given to pregnant women to accelerate fetal lung maturity before preterm delivery have been known for many years. ${ }^{2}$ Despite indisputable evidence of benefit, clinicians have been slow to adopt this treatment, and thus preventable serious morbidity and deaths continue to occur. The trial by Egerman et al evaluated a route of administration (oral) that is easier, less expensive, and probably more acceptable to women. There are, however, a few worrisome methodological problems in this study. Mothers were randomised, and therefore the data analysis should have been based on the pregnancy rather than the infant. There are 2 reasons for this: (1) one infant may have several adverse outcomes, and (2) one pregnancy may result in multiple births. A few infants with multiple problems can make it seem that a pattern of greater morbidity has occurred in one group, when only a few babies were actually affected, and these may have been the result of even fewer pregnancies. The actual number of pregnancies with a serious adverse outcome may therefore be much smaller than the numbers in the report suggest. There were 11 twin pregnancies in the oral group, compared with 6 in the control group, and the report does not tell us how many infants or pregnancies had 1 or more serious adverse outcomes. Furthermore, the trial had adequate statistical power to detect only large differences in respiratory distress syndrome, necrotising enterocolitis, and neonatal deaths.

Thus, I am left with questions about how to interpret the study results, particularly because, as the authors point out, there is no ready pharmokinetic explanation for the observed differences. Despite these questions, there is clearly no basis to conclude that oral administration of dexamethasone is as effective as the intramuscular route. Until we have clear evidence to the contrary, I agree with the trial authors that oral administration cannot be recommended.

Ellen Hodnett, RN, $\mathrm{PhD}$

Professor and Heather M Reisman Chair in Perinatal Nursing Research University of Toronto Toronto, Ontario, Canada

1 Egerman RS, Mercer BM, Doss JL, et al. A randomized, controlled trial of oral and intramuscular dexamethasone in the prevention of neonatal respiratory distress syndrome $A m$ Obstet Gynecol 1998 Nov; 179:1120-3

2 Crowley P. Prophylactic corticosteroids for preterm delivery (Cochrane Review, latest revsion 19 Jan 96). In: Cochrane Library. Oxford: Update Software. 